\title{
Factors Affecting Effectiveness of the Ethiopian Legislature
}

\author{
Afework Gizaw \& Selamawit Weldeslassie
}

\begin{abstract}
This study aimed at assessing factors affecting FDRE (Federal Democratic Republic of Ethiopia) legislature in the policy making process. Along with the use of Mixed-methods research design, both quantitative and qualitative data were collected from 162 respondents who were selected using random and nonrandom sampling technique. A self-constructed structured questionnaire and semi-structure interviews were used to gather research data from members of parliament, members of opposition parties, policy scholars and key stakeholders. Both confirmatory factor analysis and Multiple Regression Analysis were employed to analyze the data. The results indicate that three factors namely: political system; political will and space; and technical capacity are the major factors that make statistical significant contributions in the prediction of legislature's effectiveness. The study recommends that there is a timely need to widening the political space as well as to make major levels of structural and administrative system improvements to make the FDRE legislature more effective in performing its entrusted policy making role.
\end{abstract} Keywords: FDRE legislature; political system; political will and space; public policy; technical capacity

DOI: $10.7176 /$ RHSS/11-3-03

Publication date: February $28^{\text {th }} 2021$

\section{Introduction}

Many argue that the role of legislatures is vital in order to effectively fulfill their important functions in building good governance and democratic system in a nation. For instance, Remini (2007); Franchino and Holland (2008); Jonson (2005); and others contend that legislatures are critical institutions in the effective functioning of a democratic system in general and in the policymaking process in particular. Hence, representing the needs and wishes of citizens and groups; identifying problems and making policies to address them; and overseeing the implementation of policies so as to assure policies and programs are carried out legally, effectively, and according to legislative intent are among the basic important functions of legislatures. though, it is agreed that the extent and nature of the role played by legislatures in the policymaking process vary greatly from country to country (Johnson, 2005).

Regardless of the differences across countries, the effectiveness of legislatures in practicing their legislative function is being affected by different factors (USAID, 2000; Barkan, 2004).Various scholars have witnessed higher tendencies of policy implementations failures in countries where legislatures are ineffective in carrying out their policy making functions, such as lack of adequately incorporating the voices of peoples most affected by those policies. For instance, Fish (1983) argues that studying factors which influence legislatures' effectiveness in policy making is complex and challenging. However, some studies have been conducted in some part of the globe by different scholars. According to these empirical studies, weak legal authority, ineffective leadership, party affiliation, personal views and values, cumbersome and committee processes, poorly trained staff, or lack of information, legislative seniority and committee membership significantly affect legislatures' effectiveness (USAID, 2000; Watam, et al., 2010). Moreover, there are a number of reasons for an ineffective legislature. The type of political and electoral systems; political will and political space; and Technical Capacity are among the major area of concern that need to be considered while assessing legislatures' lawmaking functions (Johnson,2005). Hence, the ineffectiveness of legislatures in performing their function in the policy making process has a very negative effect on the development of a nation as well as on the wellbeing of the public at large.

The House of peoples' representatives (HoPRs) is the highest political organ, with a wide range of legislative powers (FDRE, 1995). Members are accountable to the constitution, the wish of the people and their conscience to remain loyal to their constituents. Besides, members of the parliament have the right to propose a bill. As stated in the Regulation No.6, 2008, standing committees which are the key clearance points at each stage of the legislative process are also empowered to scrutinize any bill that is referred to them. Despite all these and other powers vested in them, the FDRE parliament in general and the various standing committees as well as individual members of parliament in particular are not in a proper position to practice their powers and mandates effectively (Mulugeta, 2005; Tiruye, 2015; Kahsay, 2013; Awel, 2011).

So far, there have been considerable research outputs into the legislative function of the FDRE parliament, including the 'assessment of Institutions, Roles and Leverage in Public policymaking' (Mulugeta,2005); the oversight function of the parliament and its role in ensuring constitutionalism and accountability under the FDRE constitution' (Awel, 2011); 'the legislative process in Ethiopia' (Kahsay, 2013); the legislature's policymaking practice and challenges, and institutional capacity (Tiruye, 2015); and participation of the society in policy formulation process and the like. However, given the greater role the legislative function of the FDRE parliament can play for building democratic system, insuring good governance and the wellbeing of the citizens, it can be 
argued that little effort has been devoted to effectiveness of the policy making process in the country. Despite that the parliament is central to the building of democracy through effective policy making, factors affecting its effectiveness is less researched and warrants an investigation in to the subject.

Hence, it is important to raise the following key questions: What are the major significant factors affecting the legislature's effectiveness in the policy making process? Which of the factors, strongly contribute to the variation of the legislatures' effectiveness? What measure should be taken to make the legislature more active and effective in the policy making process? In order to answer these questions, this paper draws on a rigorous descriptive and explanatory quantitative study to explain the cause effect relationship between the main factors and legislature's effectiveness in the policy making process in Ethiopia.

Specifically, the paper identifies the key statistically significant determinants that explain the causes for the effectiveness level of the legislature throughout the policy making process. Using confirmatory factor analysis, the study analyzes 16 indicator variables and come up with factor scores for the respective three latent factors. These include the political system, political will and space, and technical capacity variables in a multiple regression model to explain the variation in the legislature's effectiveness in carrying out its legislative functions.

\section{Theoretical Frameworks of Factors Affecting Legislatures' Effectiveness}

There are several factors that affect the way legislatures carry out their basic functions in general and their lawmaking functions in particular. This section presents the major and commonly known factors that are categorized in to three types namely: political systems; political will and political space; and Technical Capacity of parliament.

\section{Political Systems}

Presidential, Parliamentary and Hybrid Systems are the three systems of government which are being practiced in the political systems across the world. All of the three political systems encompass their own unique features and are among the major factors that determine the role and independence of the legislatures and affect its effectiveness in undertaking its basic functions including lawmaking (Beetham, 2006; Szilagyi, 2009). In the presidential system, the executive and legislatures are elected independently from different constituencies for terms of different duration. In addition, cabinet members are selected by the president from constituencies other than of the parliament. Besides, many scholars argue that in the presidential form of governments not only relatively balanced power is vested both in the executive and legislature but the two branches of government are also established as two parallel structures by separation of powers. As a result, some claim that their formal power and the presence of a clear separation of power allows both structures, particularly the legislature, to develop a strong committee systems that can play an active and effective role in carrying out their lawmaking and oversight functions(USAID, 2000; Johnson, 2005; Szilagyi, 2009). Hence, most often, it is less to be expected for the executive to make the legislative branch dependent on it, so that legislatures in presidential systems are expected to play their lawmaking and oversight roles independently and meaningfully for they are encouraged by the clear division of power between them and executives the (Ibid).

In parliamentary system the head of government and cabinet members are nominated from the majority party or coalitions within the legislature whose members are elected concurrently for terms of invariant duration. According to Lijphart, as cited in Szilágyi (2009), Parliamentary forms of governments are generally categorized into two different systems namely: the Westminster, and the Consensus systems. In the Westminster system, which are not restricted but usually found in Commonwealth countries, legislatures are characterized for playing an adversarial style of debate as well as having committees which are relatively less significance than legislatures plenary session. In addition, some of the countries which implement the Westminster system, including Ethiopia, the United Kingdom and Canada use a plurality voting system to elect their legislatures. On the other hand, legislatures in Consensus system are elected using a proportional voting system and is described as best example of this model. Comparing with the Consensus systems which are identified by proportional representation and sometimes named the West German Model, the Westminster system does not allow a greater separation of powers between the legislatures and executives.

This is basically because of the fact that the leading party in the Westminster system most often has a single majority in the parliament and the fusion of the legislature and executive as well. Accordingly, the executive is more probable to get the necessary support from the legislature and this in turn leads to minimize the occurrence of overt conflict between the two branches of governments as well as the legislative authority and pressure in policymaking and oversight functions (Johnson, 2005). This fact implies that legislatures are not encouraged rather demotivated to develop a robust committee structure that have policy expertise and professional staff and can help to undertake the lawmaking as well as the oversight functions efficiently and effectively.

The hybrid system is the other form of government which can easily be distinguished drawing on both the two systems. In the the hybrid systems, which is adopted by most of the Eastern Europe, a president is elected separately and has primary responsibility in certain policy areas, while the prime minister, often times is appointed 
by the president from the legislative majority, exercises jurisdiction in other matters (Szilagyi, 2009). Hence, in the hybrid systems, not only the policy making process but the forms of conflicts also arise between the executive and legislature are dependent on the formal legislative powers vested on the two branches and 'by the traditions and history of the particular polity'. It is argued that "The hope of being named a cabinet minister, and the concern that the president can dissolve parliament can discourage members of parliaments from acting independently or contrary to the executive's will" (Johnson, 2005, p.7).

Some scholars point out that though many of the legislatures in developing countries, particularly in sub Saharan Africa, have formal legislative and oversight power, they are not using these powers properly because of the political systems they are operating with that let the executive to enjoy its dominant role. Besides, the type of political system is one of the major factors that influence legislatures' effectiveness (Eberlei and Henn, 2003; UNECA, 2005; Olusegun, 2015). As stated in the African governance report of 2005, except Namibia, South Africa, Ghana, Senegal, Mozambique and Gambia, the majority of legislatures in Africa are not free from the domination of the executive with regard to their major legislation function. The degree of the domination, resulting from the power unbalance between legislatures and executive, becomes stronger particularly in three countries, namely Swaziland, Kenya and Ethiopia. Such relative weakness may be attributed to strong executive power (UNECA, 2005).

In addition, the results of some studies points out that the presence of a very dominant ruling party and harsh party discipline and absence of effective opposition parties are the other aspects of a political system that have been affecting legislatures in performing their major core functions. In parliaments of some countries such as Benin, where such a problem existed it was found that the lawmaking and oversight functions of legislatures were undermined and strongly dominated by the executive (Barkan, 2009). In general, the degree of departure or unity between the executive and legislatures is considered as the most significant determining factor of the level of independence and potential strength of the legislatures in the policy making process.

\section{Political Will and Political Space}

Having a formal legislative power is not necessarily a guaranty for legislatures to become powerful and independent institutions. They further need to have a strong desire and political will to enlarge their power and exercise them accordingly (UNECA, 2005). Besides, other dominant players of the political game including executives and political parties should also be willing to share adequate and meaningful political power with legislatures. Most argue that legislatures in more pluralistic and competitive political systems are allowed more political space by far than legislatures in authoritarian political systems. Moreover, the fact that whether legislatures that are dominated by strong party discipline are allowed to use and expand the available political space or not is highly dependent on the disposition of the political party (Johnson and Nakamura, 1999).

Accordingly, political will and political space is found to be another important factor that affected the power and independence of legislatures not to perform their roles effectively. In relation to this, the results of some studies have showed that legislatures in Africa, most often, failed to perform the in legislative and oversight role appropriately because of the low perception they have regarding their relevance. Hence, members of the legislatures tend to depend on the executive for they lack the confidence and willingness to deliver checks and balances on the excesses of the executive. It is also due to lack of a virile opposition politics (Barkan, 2004; Olusegun, 2015). Moreover, it was revealed that many legislatures in Africa were not willing to reflect the needs and aspirations of their constituencies properly since their members are not well informed and able to carry out such activities (Saigegh, 2005). Having this in mind, it may be fair to conclude that the political will and political space are of the very crucial factors in order to make legislatures exercise their legislative power meaningfully.

\section{Technical Capacity}

Technical Capacity is also the other most essential determinant as to how legislatures are able to effectively exercise their major functions such as lawmaking. Legislature's technical capacity encompasses a number of issues including management capabilities such as effective organizational and administrative structures, processes, and rules; the ability to have a system to meet their unique information needs in relation with the various aspects such as technical or policy components of decisions; the ability to fulfill the required space, equipment and trained staff; and the ability to properly mobilize resources needed to undertake their activities dynamically etc (Beetham, 2006).

For instance, one of the significance of good management capabilities is the ability to improve record-keeping mechanisms for it helps to improve the performances of legislatures and to make them more accessible and transparent to citizens. A legislature that has its own sources of information and the ability to fulfill its required needs is more likely to be less dependent on either the lobbyists or the executive throughout the lawmaking process. Such capacities have their own role in making the legislatures to be significantly effective in performing their activities (USAID, 2000; Johnson, 2005). In support of this principle, Beetham (2006) also argues:

Where parliaments lack capacity through limited resources, this inevitably affects the balance of 
power with the executive. Parliament's oversight work is less rigorous; members become dependent upon the expertise of government staff whose first allegiance is to the executive; governments may simply bypass parliament altogether in the development of policy and legislation. If parliament is consequently seen to be less relevant by the public, or its role is not understood, this may in turn affect its capacity to claim additional resources from a restricted national budget (p.118).

Lack of adequate technical capacity is also one of the the other important determinant factors that affects the legislative power and independence in Africa and more broadly across the developing world. Many legislatures in Africa were found to be dependent and to a large extent ineffective to perform their core functions efficiently and effectively for they lack the required technical capacity. Hence, legislatures' ineffectiveness is rooted in the lack of institutional capacity; basic infrastructural problems; and the inability of legislatures themselves, for majority of them are not well equipped with the necessary knowledge, skills and experience to carry out their major functions (Onigbinde, 2000; Eberlei and Henn, 2003; Olusegun, 2015). For instance, in Kenya and Sesotho have set the ability to read and write as a sufficient minimum educational standard for MPs (UNECA, 2005). Beetham (2006) also found out that the effectiveness of most of legislatures in developing countries was affected by the lack of resources and staff with the appropriate expertise. As he argued, insufficiency of support staff and the skills of the available staff were the major causes for the limitations of legislatures in countries such as South Africa. By contrast, it was revealed that the technical capacities of legislatures in some African countries such as Chad, Mali, Nigeria, South Africa and Tanzania were shown incrementally enhancement resulting the trend of parliamentary debate to significantly grow (UNECA, 2005).

There are also other evidences that technical capacity is not only the problem of developing countries but is equally that of the developed one's. For instance, a study by Korris (2011) has found out that regardless of some significant enhancements in the parliamentary process, the scrutiny system in the UK's parliament was not fit for purpose since the legislatures lack adequate resource and expertise which is required to effectively undertake the scrutiny function.

Hence, whether legislatures have formal legislative power or not, it is difficult for them to carry out their legislative function effectively if they don't have the necessary technical capacity to perform their role as desired.

\section{Research Methodology}

\section{Purpose, Sampling, and data collection methods}

The aim of this research was to determine the major statistically significant factors that affect legislature's effectiveness in policy making process in Ethiopia. Parallel to this main objective, its sub-goal is to determine the unique contribution of each of the factors and their indicator variables in explaining the variation of the legislature's effectiveness throughout the legislative process.

\section{Sampling Method}

All members of the FDRE HoPRs were the target population of this study. In addition, members of the Ethiopian Federal Democratic Unity Forum (Forum), and Blue Party, the Ethiopian Civil Service University's Center for Public Policy Studies (CPPs), and Addis Ababa University's department of Public Management and Policy (DPMP) administrators, instructors and graduating students were also included as key informants.

Sampled members of the parliament (MPs) from the total population based on a two-stage random sampling procedure were selected. Moreover, using stratified sampling technique the total population was split into a group of committees which are alike based up on the characteristic that is shared in the group such as powers and responsibilities. After determining the number of individual MPs to be included from each stratum (committee) through proportionate stratified sampling technique, the appropriate sample size from the population was determined using the simplified formula which is provided by Cochran (1963). To calculate the appropriate sample size, it was desired $95 \%$ confidence level; $20 \%$ proportion for there existed a minimum variability in the large majority of target population, $\pm 7 \%$ Precision. Then, by applying the formula, the sample size became 120 . Since the target population is small, was further reduced slightly using the following equation

Equation $2 \quad n=\frac{\text { no }}{1+\frac{(\mathrm{no}-1)}{N}}=\frac{125}{1+\frac{(125-1)}{547}}=102$

In addition to MPs, members of two opposition political parties public similarly, two policy scholars who were believed to help get more balanced responses were made part of the sample. For instance, Forum of opposition political parties has a greater number of $\mathrm{x}$-MPs as well as it can be taken as a representative of national political (opposition) parties that formed a forum. Besides, Blue Party is the party that got the second highest result in the 2015 national election. Furthermore, both parties did run for the 2007 national election having more than 100 candidates (electoral board, 2014). Similarly, respondents from the CPPs and DPMP who have adequate information and good expertise in the public policy discipline were included into the study. In summary, generally, a total 102 MPs, 20 respondents from the two opposition parties, 25 public policy scholars, and 15 key stakeholders were made to fill in the questionnaire. The total number of respondents of the study was 162 . Besides, 8 more 
respondents were purposively identified for the interview.

\section{Questionnaire: Design, Rationale, Pilot Study and Data Collection}

On the basis of various literatures and empirical studies that deal with the topic under investigation, a questionnaire that had three parts with 21 close-ended and 3 open-ended questions was designed. Moreover, an additional demographic data of respondents were taken. Research questionnaires were selected for the following reasons. Firstly, as Gray (2013), noted a questionnaire is efficient in terms of both time and money; it allows getting quick inflow of data from many people at a time; and it further gives a chance for respondents to complete the questionnaire at a time and place that suits them. Secondly, it offers a methodology to make the coding and data analysis of, especially close-ended questions, relatively simple and quick.

Before undertaking the data collection, a pilot study was conducted using two steps so as to enhance the reliability, validity, and practical application of the questionnaire. Firstly, they were presented to some senior professional staff members of CPPS and AAU, who have good expertise in the policy making process, to rate the relevance and appropriateness of each item and to provide necessary comments. Secondly, they were distributed to $10 \mathrm{MPs}, 2$ experts at HoPRs, 1 graduating student, and 2 members of opposition parties who were most directly experienced with the case under investigation. Accordingly necessary refinements were made based on their feedback. Five items were discarded and a further modified questionnaire was made ready for approval. Hence, the final questionnaire having a total of 19 (16 open-ended, and 3 close ended, excluding demographic data) were administered. During the data collection phase a total of 162 questionnaires were distributed to the sample respondents of which $84 \%$ questionnaires were returned, and $80 \%$ were taken as valid responses and the remaining $4 \%$ were discarded for many items were left blank.

\section{Interview}

Interview was also used in order to gather qualitative data so as to strengthening the validity of the finding from other instruments as per the strengths associated with triangulation. In consequence, a total of 8 semi-structured interview questions were conduct the interview with the deputy speaker of the House, one directorate director at the HoPRs, three top-leaders of the two opposition parties, one former MP, the director of CPPS at ECSU, and a senior instructor in PADM at AAU. Most of the interviews were taped and each interview session lasted for an average of 40 minutes.

\section{Method of Data Analysis}

A multiple regression model was used to determine the effects of political system, political will and political space, and technical capacity on the effectiveness level of FDRE legislature in the policy making process. It was also found important that all the independent and dependent variables are latent constructs which are difficult to measure directly. Therefore, on the basis of the literature review, a total 16 indicator variables were identified to measure the latent constructs that represent the major factors affecting legislature's effectiveness in the policy making process. Moreover, a hypothesized model of the research that consists of a total of 16 indicator variables, three extraneous latent factors, and one endogenous latent factor were developed (see appendix A). Finally a Structural Equation Modeling (SEM) specifically a confirmatory factor analysis (CFA) was used in order to ascertain the validity and reliability to empirically confirm the hypothesized model fitness. The CFA served as a tool to create a factor score using data imputation technique for each of the latent constructs that were included in the multiple regression models. The following sub-sections explain the results of the CFA as well as the analytical strategy employed.

\section{Confirmatory factor analysis}

Fornell and Larcker (1981) recommended that the following three criteria are essential to establish convergent validity: 1) the ideal level of standardized factor loadings (SFL) of construct items should be significant and exceed 0.70. On the other hand, other scholars suggest that 0.60 is considered to be an acceptable level (Barclay et al., 1995); 2) Construct factor loadings (CFL) must be greater than 0.50; and 3) Average Variance Extracted (AVE) must exceed 0.50 . Accordingly, each of these criteria was tested so as to verify convergent validity in this study. With regard to the first criteria, the standardized factor loadings for all construct items/reflective indicators (observed variables) were greater than 0.60 and statistically significant (see appendix A). In the case of the second and third criteria, the CFL as well as the AVE were manually calculated using the formula recommended by Fornell and Larcker (1981), and both the AVE and CFL values for all constructs (except TC/0.34/) were found to be greater than 0.05 .

Hair, et al., (1998) argued that the degree of consistence among various dimensions of variables can be assessed by means of reliability analysis. It measures the overall reliability of a set of construct items loaded on a latent construct. Though values greater than 0.70 reflect good reliability, a value between $0.60-0.70$ is also satisfactory if extra indicators of the construct's validity are good (Fornell and Larcker, 1981; Hair et al., 1998). 
Hence, the internal reliability of the measurement model was tested using Fornell's composite reliability formula. Accordingly, all composite reliabilities of all constructs have indicated a value higher than 0.70 , except TC which has an approximate value of 0.70 , indicating relatively an adequate internal consistency. Therefore, in this study, it can be concluded that convergent validity as well as composite reliability were established since all the criteria mentioned above were satisfied. The CFL, AVE and CR results are presented in (see appendix B).

We also used two goodness-of-fit statistics to assess the adequacy of the hypothesized model. Accordingly, though the chi square index yielded $\mathrm{x} 2$ value of 76.390, with 51 degrees of freedom and a probability value (0.012), suggesting inadequacy of the fit of the data to the hypothesized model, other goodness-of-fit indices, the $\mathrm{x}^{2} / \mathrm{DF}$ ratio was $1.498\left(\mathrm{x}^{2}=76.390 ; \mathrm{DF}=51\right)$, indicating acceptable model fit. Moreover, computed other five common goodness-of-fit fit measures were computed in order to further assure the adequacy of the models. The results of the AGFI, CFI, RFI, TIL, and RMSEA were 0.86; 0.97; 0.91; 0.96; and 0.06, respectively. Besides, all path coefficients were found statistically significant at $\mathrm{p}<0.01$ indicating a significant contribution of each item to the related factor (see appendix $\mathrm{C}$ ). The results revealed that the three factor hypothesized model structures that emerged and confirmed to be a good fit with the data collected from sample respondents. After this, it was created factor scores for all the four latent constructs using data imputation technique. In other words, the findings came up with four new continuous variables, each representing the three independent variables (political system, political will and political space, and technical capacity) and one dependent variable (legislature's effectiveness).

\section{Analytical strategy}

A descriptive statistics was employed to make sense out of the numerical data from the questionnaire. To this end, statistical techniques such as frequency distribution and test of proportions to describe present and interpret the distribution of, and relationships among different variables were used. Confirmatory factor analysis was conducted to evaluate and determine the fitness of hypothesized model with the data collected from 130 respondents. Besides, the study employed regression analysis in order to analyze the significance, direction and strengths of the relationships between and/ or among the variables and groupings. Furthermore, AMOS version 23, SPSS version 22 and Microsoft excel for processing the tabulation of quantitative data was used to make the data analysis more efficient. In addition, these measures served to encode data, calculate, and generate some graphs. Besides, a content analysis method was used to systematically analyze data from the interview, and the open ended part of the questionnaire in order to determine and surface some underlying factors which contribute to the improvement of the legislative`s role in the policy making process. Moreover, was accompanied both by the quantitative data with the qualitative data, and vice versa, since it is a concurrent mixed method that was applied in this study.

\section{Results and Discussion}

This section presents the results and discussion of the study in two parts. Firstly, the result and discussion of the factors affecting legislature's effectiveness in the policy making process in Ethiopia is presented. Secondly, the result of the analysis about the effect of the indicator variables on the dependent variable is shown. In presenting the result, a particular attention was given to address issues such as whether there is a statistically significant correlation between Political System and legislatures' effectiveness: if the response was yes, in which direction and how strongly they are correlated; and how much of the variation in the effectiveness of FDRE legislatures' effectiveness is explained by the factors. Furthermore, it was assessed the statistical significance contribution of each of the indicator variables of the factor in predicting the outcome variable. In general, it could be considered appropriate analyses were made as part of the multiple regression analysis to check basic assumptions of multiple regression namely: normality, linearity, homoscedasticity, and multicollinearity. The results suggest that there was no major deviation from normality; there is a linear relationship between the each of the independent variables and the dependent variable. Moreover there was no violation of multicollinearity assumption. The results of these tests are annexed in annex D, and E. 
Predicting FDRE legislature's effectiveness from political system, Political Will and Space, and technical capacity

Table 2: Regression Result for Factors Predicting Legislature's Effectiveness

\begin{tabular}{|c|c|c|c|c|c|c|}
\hline \multirow[t]{2}{*}{ Variable } & \multirow[t]{2}{*}{ Model 1} & \multirow[t]{2}{*}{ Model 2} & \multicolumn{4}{|c|}{ Model 3} \\
\hline & & & B & Beta & $\mathrm{Sr}$ & Pratt \\
\hline Constant & $2.510(.072)$ & $2.377(.072)$ & $2.545(.092)$ & & & \\
\hline Political system/PS/ & $.862(.053)^{* * *}$ & $.421(.121)^{* *}$ & $\begin{array}{c}.409 \\
(.117)^{* *}\end{array}$ & .390 & .161 & .320 \\
\hline $\begin{array}{l}\text { Political Will and Space } \\
\text { /PWS/ }\end{array}$ & - & $\begin{array}{c}.661 \\
(.165)^{* * *}\end{array}$ & $\begin{array}{c}.431 \\
(.176)^{*}\end{array}$ & .302 & .112 & .250 \\
\hline Technical Capacity (TC) & - & - & $\begin{array}{c}-.413 \\
(.134)^{* *}\end{array}$ & -.222 & -.141 & .162 \\
\hline R square & .677 & .713 & \multicolumn{4}{|c|}{.733} \\
\hline Adjusted R square & .675 & .709 & \multicolumn{4}{|c|}{.727} \\
\hline Sig & .000 & .000 & \multicolumn{4}{|c|}{.000} \\
\hline
\end{tabular}

Source: Survey Data, 2015/16

Note. The Dependent Variable is FDRE legislature's effectiveness/LEF/; $N=130 ;{ }^{*} \mathrm{p}<.05, * * \mathrm{p}<.01,{ }^{*} * \mathrm{p}<.001$; Numbers in brackets are standard errors; $\mathrm{Sr}$ is semi-partial correlation; Pratt is product measure.

Model 1 includes only Political System /PS/ in a simple regression equation explaining legislature's effectiveness /LEF/. The estimated equation is:

$$
\mathrm{LEF}=2.510+.862(\mathrm{PS})
$$

Model 1 further indicates that there is a strong positive relationship between Political System and legislature's effectiveness. Besides, the slop coefficient on PS is statistically significant and implies that a unit increase in Political System is predicted to increase legislature's effectiveness by 0.862 . Furthermore the R square value of model 1 implies that Political System explained about $67.7 \%$ of the variation in legislature's effectiveness at $0.1 \%$ significance level.

As can be seen in table 2, model 2 includes political system/PS/ and Political Will and Space/PWS/ in an equation explaining LEF. The estimated equation is:

$$
\mathrm{LEF}=2.377+.421(\mathrm{PS})+.661(\mathrm{PWS})
$$

In addition, Model 2 shows that there is a positive partial relationship between Political System (PS) and legislature's effectiveness: holding Political Will and Space constant, and vice versa. As in case of model 1, the coefficient on PS has same interpretation. The only difference is that it also has a ceteris paribus interpretation. Accordingly, the slop coefficient on PS is statistically significant and implies that, holding PWS fixed, a unit increase on PS is associated with 0.421 of increase on LFE. Besides, the slop coefficient on PWS is also statistically significant implying that, while holding PS constant, a unit increase in PWS affects LEF by 0.661 . This is a large effect, and it suggests that, once PS is accounted for, the PWS is a strong predictor of LEF. Furthermore, model 2 shows that, PS and PWS together explained about $71.3 \%$ of the variation in LEF, $(F(2,127)=158.05, p<.001)$.

Thus, adding PWS in model 2, since it leads to change in R square from .677 to .713, explained an additional $3.6 \%$ of variation in legislature's effectiveness and this change in $\mathrm{R}^{2}$ was significant, $(\mathrm{F}(1,127)=16.068, \mathrm{p}<.001)$. This result indicates that Political Will and Space factor does really account for a significant amount of variance above and beyond Political System factor. This finding also supports other researchers' findings (Babatope, 2001; Olusegun, 2015). Barkan (2004), for instance, found out that MPs tend to be dependent on the executive for they lack the confidence and political will to deliver checks and balance on the executive.

As shown in table 3, model 3 includes PS, PWS, and TC in an equation explaining LEF. The estimated equation is:

$$
\mathrm{LEF}=2.545+.409(\mathrm{PS})+.431(\mathrm{PWS})-.431(\mathrm{TC})
$$

As revealed in model 3 , there is a positive partial relationship between PS and LEF: holding PWS and TC constant. There is also a positive partial relationship between PWS and LEF: holding PS and TC constant. By contrast, there is a negative partial relationship between TC and LEF: holding, PS and PWS constant. Accordingly, the coefficient 0.409 implies that, holding PWS and TC constant, a unit increase on PS is predicted to increase LEF by 0.409 . Similarly, a unit increase on PWS affects LEF by 0.431 , holding PS and TC constant. On the contrary, the negative sign on the coefficient of TC implies that, holding PS and PWS constant, a unit increase on TC is predicted to decrease LEF by 0.413 .

Furthermore, the result indicates that political system, Political Will and Space, and Technical Capacity together explained about $73.3 \%$ of the variation in effectiveness of FDRE legislature in the policy making processes, $(\mathrm{F}(3,126)=115.494, \mathrm{p}<.001)$. In general, the results suggest that the aggregated model 3 which includes political system, Political Will and Space, and Technical Capacity is the best of all the three models for it explains the highest percent of variation in legislature's effectiveness. It is also revealed that adding TC in model 
3 increases R square from .713 to .733. Thus, Technical Capacity is explained as an additional $2 \%$ of the variation in legislature's effectiveness and this change in $\mathrm{R}^{2}$ was significant, $(\mathrm{F}(1,126)=9.417, \mathrm{p}<.01)$. This result implies that Technical Capacity as a factor accounts for a statistically significant amount of variance above and beyond both the political system, and Political Will and Space factors. This finding is in harmony with those researches such as Onigbinde (2000) and Beetham (2006) who revealed most legislatures in Africa and more broadly across the developing world are, to a large extent, ineffective to perform their legislative functions for they lack adequate technical capacity.

A further analysis was conducted in order to compare and assess the strength of the relationship between each independent variable to the dependent variable. Accordingly, PS is found to be the strongest direct predictor of LEF across multiple indices. For instance, PS obtained the largest beta weight $(\beta=.390, p<.01)$, demonstrating that it made the largest contribution to the regression equation, while holding all other predictor variables constant. The semi-partial correlation of PS with the LEF $(\mathrm{Sr}=.161)$, when squared, further showed that PS shared the largest amount $(2.5 \%)$ of its variance with LEF. In addition, Product measure results demonstrated that PS accounted for the largest partition of variance in LEF $(.320,44 \%$ of the regression effect) when multiplying the beta weight (.39) by the zero-order correlation (.823). The overall values indicate that PS is the major factor that made the largest statistically significant contribution to the prediction of legislature's effectiveness in the policy process. This finding is broadly in agreement with the conclusion of Eberlei and Henn(2003); UNECA(2009); and Olusegun (2015) that confirmed Political System is one of the major factors that influence legislature's effectiveness.

Similarly, these statistics clearly showed that PWS was the second stronger direct contributor to the regression equation, followed by TC. The second beta weight $(\beta=.302, p<.05)$, was obtained by PWS implying the fact that that it made the larger contribution to the regression equation than TC, while holding all other predictor variables constant. The semi-partial correlation of PWS with the LEF $(\mathrm{Sr}=.112)$, when squared, showed that PWS shared the least amount (1.2\%) of its variance with LEF. Despite of this finding, the Product measure results demonstrated that PS accounted for the second larger partition of variance in LEF (.250, $34 \%$ of the regression effect) when multiplying the beta weight (.302) by the zero-order correlation (.828). On the basis of the overall result, it can be concluded that PWS is the second factor that made the larger statistically significant contribution to the prediction of legislature's effectiveness in the policy process, followed by TC.

Put it differently, the result reveled that TC was the least contributor to the regression equation. TC's beta weight $(\beta=-.222, p<.01)$, demonstrating that it made the least contribution to the regression equation, while holding all other predictor variables constant. The semi-partial correlation of TC with the LEF $(\mathrm{Sr}=-.141)$, when squared, showed that TC shared the larger amount (1.9\%) of its variance with LEF, followed by PWS. Product measure results demonstrated that TC accounted for the least partition of variance in LEF $(.162,22 \%$ of the regression effect) when multiplying the beta weight (-.222) by the zero-order correlation (-.732). On the whole, it can be concluded that TC, though it is the least one, is still a statistically significant contributor of the variance in, the predicted values of LEF.

\section{Predicting FDRE legislature's effectiveness from the groups of indicator variables}

Table 3 below shows, there is a statistically significant strong, positive correlation between each of the first two indicators (loyalty /PS1/ $[\mathrm{r}=.74, n=130, p<.000]$, and separation of power/ PS2/ $[\mathrm{r}=.74, n=130, p<.000]$ ) and legislature's effectiveness. The result implies that, when levels of MPs loyalty to the constitution, their conscience, and the public gets higher it is associated with high level of legislature's effectiveness, and the implication is also true for the second indicator variable. On the other hand, there is a strong negative correlation between the measures taken on MPs/PS3/ $[\mathrm{r}=-67, n=130, p<.000]$ and legislature's effectiveness indicating that an increase of measure taken on MPS is associated with lower levels of legislature's effectiveness. Similarly, there was a strong negative correlation between absence of opposition parties in parliament/ PS4/ $[\mathrm{r}=-.767, n=130, p<.000]$ and the dependent variable. This result implies that the absence of opposition parties in parliament is, again, associated with lower levels of Legislature's effectiveness. 
Table 3: Regression Results for Indicator Variables Predicting Legislature's Effectiveness

\begin{tabular}{|l|l|l|l|l|}
\hline Variable & Pearson $\mathrm{r}$ & Model 4 & Model 5 & Model 6 \\
\hline Constant & & $2.602(.463)$ & $2.283(.636)$ & $1.969(.745)$ \\
\hline Loyalty(PS1) & $.747^{* * *}$ & $.235(.074)^{* *}$ & $.081(.081)$ & $.104(.082)$ \\
\hline Separation of power (PS2) & $.745^{* * *}$ & $.233(.080)^{* *}$ & $.101(.083)$ & $.113(.083)$ \\
\hline Measure taken(PS3) & $-.673^{* * *}$ & $-.032(.083)$ & $.052(.085)$ & $.085(.084)$ \\
\hline Absence of opposition parties(PS4) & $-.767^{* * *}$ & $-.295(.057)^{* * *}$ & $-.232(.057)^{* * *}$ & $-.226(.057)^{* * *}$ \\
\hline Total freedom (PWS1) & $.728^{* * *}$ & - & $.212(.077)^{* *}$ & $.164(.079)^{*}$ \\
\hline Negative influence (PWS2) & $-.725^{* * *}$ & - & $-.172(.109)$ & $-.124(.108)$ \\
\hline Adequate knowledge (PWS3) & $.634^{* * *}$ & - & $.095(.068)$ & $.059(.067)$ \\
\hline Freedom of speech (PWS4) & $.671^{* * *}$ & - & $.118(.065)$ & $.054(.067)$ \\
\hline Agenda setting power (TC1) & $-.654^{* * *}$ & - & - & $-.037(.078)$ \\
\hline Time allotment (TC2) & $.515^{* * *}$ & - & - & $.057(.058)$ \\
\hline Stru. \& admin. System (TC3) & $.568^{* * *}$ & - & - & $.144(.062)^{*}$ \\
\hline Rules \& regulation (TC4) & $-.529^{* * *}$ & - & - & $-.044(.065)$ \\
\hline R & & .839 & - & .874 \\
\hline R square & & .704 & .741 & .763 \\
\hline Adjusted R square & & .694 & .724 & .739 \\
\hline R square change & & .704 & .038 & .022 \\
\hline F-statistics & & $74.21^{* * *}$ & $4.413^{* *}$ & $2.863^{*}$ \\
\hline Sig & & .000 & .000 & .000 \\
\hline Sig: Survy Dat 2016 & & &
\end{tabular}

Source: Survey Data, 2016

Note. The Dependent Variable is LEF; $\mathrm{N}=130 ;{ }^{*} \mathrm{p}<.05,{ }^{* *} \mathrm{p}<.01,{ }^{* * *} \mathrm{p}<.001 ;$ Numbers in brackets are standard errors; $\mathrm{Sr}$ is semi-partial correlation; Pratt is product measure.

As can be seen in table 3, model 4 includes four indicator variables of the Political System /PS/ (loyalty, separation of power, measure taken, and absence of opposition parties) in a simple regression equation explaining legislature's effectiveness /LEF/. The estimated equation is:

$$
\mathrm{LEF}=2.602+.235(\mathrm{ps} 1)+.233(\mathrm{ps} 2)-.032(\mathrm{ps} 3)-.295(\mathrm{ps} 4)
$$

It was indicated that the slop coefficient on PS1 is statistically significant and implies that a unit increase in ps1 is predicted to increase legislature's effectiveness by .235. Accordingly, the coefficient .233 implies that holding other variables constant, a unit increases on ps2 is predicted to increase LEF by .233. On the contrary, the negative sign on the coefficient of ps4 implies that holding other variables constant, a unit increase on ps4 is predicted to decrease LEF by .295. Unlike the other indicator variables, whether administration measure is taken on MPs or not, since its p-value is $>.05$, it has no a statistically significant contribution in explaining the variation of the LEF, holding other indicator variables constant. Furthermore, the variables entered in model 4, as a group, explained about $70 \%$ of the variation in legislature's effectiveness, $(F(4,125)=74.211, p<.001)$. Though the value seems a high percentage, however it should be noted that the model does not consider the possible overlapping effect of the indicator variables of the other two factors (PWS and TC).

In model 5, the next group of independent variables (total freedom, negative influence, adequate knowledge, and freedom of speech) was entered into the 'equation' as a block, while the possible effect of political factor indicator variables have been 'removed' in order to assess whether the block of independent variables included in model 5 are able to explain some of the remaining variance in legislature's effectiveness. The estimated equation is:

$$
\begin{gathered}
L E F=2.283+.081(P S 1)+.101(p s 2)+.052(p s 3)-.232(p s 4)+.212(p w s 1)-.172(p w s 2)+.095(p w s 3) \\
+.118(p w s 4)
\end{gathered}
$$

The result for Model 5 shows that there is a statistical negative significant relationship between PS4 and LEF, and a statistical positive significant relationship between PWS1 and legislature's effectiveness: holding other variables constant. On the other hand, none of the remaining indicator variable is found to have a statistical significance contribution to predict the variation on legislature's effectiveness. Furthermore, it indicates that all the 8 indicator variables together explained about $74 \%$ of the variation in $\operatorname{LEF},(F(2,127)=158.05, p<.001)$. Thus, adding PWS indicator variables in model 5 leads to change in R square from .704 to .741, explaining an additional $3.8 \%$ of variation in legislature's effectiveness and this change in $\mathrm{R}^{2}$ was significant, $(\mathrm{F}(4,121)=4.413$, $\mathrm{p}<.01)$. This result indicates that Political Will and Space factor's indicator variables, as a group, do account for a significant amount of variance above and beyond Political System indicator variables (loyalty, separation of power, measure taken, and absence of opposition parties.).

Finally, the last group of indicator variables (agenda setting power, time allotment, structural and administration system, and rules and regulations) was added as a block in model 6 . The result indicates that the overall model (Model 6) explains 73.9 per cent of the variance in legislature's effectiveness at $0.1 \%$ significance 
level, $(\mathrm{F}(12,117)=31.412, \mathrm{p}<.001)$. Since the overlapping effect of political factor, as well as Political Will and Space factors' indicator variables have been controlled, it was possible to evaluate the unique contribution of the variables entered in model 6 to predict a significant amount of the remaining variance in legislature's effectiveness. Hence, the finding suggest that, adding a group of four variables (agenda setting power, time allotment, structural and administration system, and rules and regulations) to the regression model explained an additional $2.2 \%$ of the variation in legislature's effectiveness and this change in $\mathrm{R}^{2}$ was significant, $(\mathrm{F}(4,117)=2.683, \mathrm{p}<.05)$. This result implies that, block 3 variables as a group accounts for a statistically significant amount of variance above and beyond both block 1 and block 2 variables.

The result revealed in Model 6 further shows that of the 12 variables, where there are only three variables (absence of opposition parties, total freedom, and structural and administration system) that make unique, and statistically significant, contribution to the prediction of legislature's effectiveness. On the other hand, the remaining nine variables were not found to be significant predictors of legislature's effectiveness while controlling for the overlapping effects of other indicator variables in the overall model.

In addition, it was compared that the relative unique contribution of the three variables that are a statistically significant predictors on the basis of their standardize Beta, semi partial correlation and product measure value. As can be seen in model 6, absence of opposition parties/ps4/ is the strongest predictor of LEF. For instance, its Beta weight $(\beta=-.297, p<.001)$, revealed that it made the largest contribution to the regression equation, while holding all other predictor variables constant. Besides, its semi-partial correlation with the legislature's effectiveness ( $\mathrm{Sr}=-.180)$, when squared, further showed that PS4 shared the largest amount (3.2\%) of its variance with the effectiveness of the FDRE legislature. The Product measure results also demonstrated that absence of opposition parties in the House accounted for the largest partition of variance in LEF $(.227,54 \%$ of the regression effect) when multiplying the beta weight (-.297) by the zero-order correlation (-.767). The overall values indicate that absence of opposition parties in the FDRE parliament is the strongest indicator of the underlying variable (PS) that makes the largest statistically significant contribution to the prediction of FDRE legislature's effectiveness in the policy making process, when the overlapping effects of all other variables were statistically removed.

In addition, as indicated in Table 3 , functioning with total freedom/pws $1 /$ is the stronger and significant direct predictor of LEF, than TC3. The value of their beta $(\beta=.160, p<.05 ; \beta=.132, p<.05$, respectively) indicates that functioning with total freedom made the larger contribution to the regression equation than adequacy of structural and administration system, while holding all other predictor variables constant. The squared semi-partial correlation of PWS1 with the LEF $\left(\mathrm{Sr}^{2}=.008\right.$ or $(.8 \%)$, when compared with the squared semi-partial correlation of adequacy of structural and administration system $\left(\mathrm{Sr}^{2}=.010\right.$ or $\left.1 \%\right)$, showed that functioning with total freedom shared the least amount $(0.8 \%)$ of its variance with LEF. However, the Product measure results demonstrated that PWS1 accounted for the second larger partition of variance in LEF (.116, $28 \%$ of the regression effect) when multiplying the beta weight (.160) by the zero-order correlation (.728). On the other hand, the Product measure results demonstrated that TC3 accounted for the least partition (18\%) of variance in LEF. Therefore, based on the overall results of the multiple indices, it can be concluded that functioning with total freedom is, indicator of the PWS factor, the second statistically significant contributor to the prediction of legislature's effectiveness in the policy process, followed by adequacy of structural and administration system.

It was also cross-tabulated the findings of the regression analysis with the findings of both the quantitative and qualitative data collected through the questionnaire, and the interview. Hence, the result and discussion of which is presented below in relation with the three indicator variables that made a statistical unique contribution to explain the variation in the legislature's effectiveness.

Regarding the absence of opposition parties in the House, of the respondents $60 \%$ of them responded 'agree' confirming that it is negatively affecting FDRE legislature's effectiveness in the public policy making process. On the other hand, $40 \%$ of the respondents disagreed that absence of opposition parties is not negatively affecting FDRE legislature's effectiveness. however, the test of proportions' result, as (Zcal $=2.236068>Z(\alpha / 2=1.96)$, indicates that the respondents who agreed were the majorities since their proportion was significantly different from those who disagreed. the interesting thing in this result was that all respondents were able to reflect what they perceived about the impact of the absence of opposition parties in the FDRE legislature effectiveness regarding the policy making process. In contrast, all of the interviewees explained that the absence of opposition parties is one of the main issues that are negatively affecting the effectiveness of legislature in the policy making process.

In the case of 'functioning with total freedom', it is notable from the descriptive analysis of the questionnaire that, 67(51.6\%) respondents agreed that MPs are undertaking their legislative function with total freedom, but $5(39.2 \%)$ of them disagreed with the issue. However, the Z-test result which was 0.263027 indicates that there is no a statistically significant differences between the proportion of the responses of respondents who agreed with those of respondents who disagreed. In order to judge whether MPs are undertaking their core functions in general and their legislative function particularly, it is very important to show what were responded by some of the interviewees for a little bit different but highly related question with the topic under discussion. For instance, one respondent explained the following: 
As far as my knowledge is concerned, there is no such a regulation that is being implemented on MPs which is creating a problem on our legislative and oversight function. I do not remember any MPs who complain stating that such and such regulation or rule is creating a problem on my job. Of course, there are performance differences among committees as well as individual MPs. Some are so active and more effective; others may not have such strength. Nowadays, there are a number of MPs who are active and courageous. Few MPs may not be like that. And it is obvious that, here and there, there are evidences of implementation problems. But, I can assure you that the difference has nothing to do with the negative influences of rules and regulation, unless our commitment or confidence level inhibited us.

On the other hand, of the 6 interviewees 5 of them have strongly argued that MPs are not functioning with total freedom because of the existence a number of negative influences that emerge from the ruling party and imposed on MPs. In this regard, one of the interviewees explained the following:

It is impossible to accept the saying that FDRE legislatures are loyal to the constitution, their conscience, and the public. For your surprise, in the history of the FDRE parliament, no single member of the parliament who is also the member of the ruling party, have proven his/her loyalty to either the constitution or the public. This is because of the dominance of the ruling party which is manifested through the very strict and harsh party discipline. What I believe is that the parliamentarians are not ready to protect their own individual independence, let alone being loyal to the people.

Similarly, another interviewee contended that one of the major sources of the FDRE legislature ineffectiveness in undertaking its major function including the legislation function which is highly related to 'the rule' of the ruling party. The interviewee's idea was presented as follows:

We all know that the highest legislative power is given to the FDRE parliament. It is clearly stated in the constitution. That is not the problem. The problem is MPs are not free and confident to exercise their formal power. The practical role of the FDRE legislature in the public policy making is very insignificant. It is even below the "talk and shop" role. The reason behind is the principle, you can call it the giant rule of EPRDF, which is called democratic centralism. They (MPs) have to obey whatever they are told to do by the higher officials of the party. Ask them what will happen if they say 'no'. In my opinion, as far as this rule remain applicable on the MPs, it will be impossible to have a parliament which is independent, powerful and effective.

The analysis of the overall results implies that, since majority of MPs are also the member of the ruling party they preferred to vote in favor of the interest of their party regardless of their disagreement with the issue that requires their decision. In other words, they are not totally free to decide as per their conscience but their party's decision.

In relation to the structure and administrative system of the House, except one, all of the interviewees believed and argued that there are a number of problems with regard to the adequacy of the structure and administrative system of the House. Similarly, many of the respondents in the open-ended part of the questionnaire indicated that there are various problems related with the issue under discussion. Having this in mind, it was a surprising result to found that the majority of the respondents, when responded to the close-ended question, showed their agreement indicating that the structural and administration system of the House was adequate. However, taking into consideration the overall results of obtained from both quantitative and qualitative data, it can be fairly concluded that structure and administration system of the House is not adequate enough to carry out the legislative function effectively. The implication is that such inadequacy of the structure and administrative system has its own unpleasant effect in reducing the level FDRE legislature's effectiveness in the public policy making process in the country.

\section{Conclusion and Recommendations}

The study was set out to analyze and discover the major statistically significant factors that are seriously affecting the FDRE legislature's effectiveness in the public policy process. Majority of previous empirical studies that dealt with the power and effectiveness level of the FDRE parliament were inconclusive on several vital questions such as: what are the factors that have a statistical significance effect on effectiveness in the public policy making process? Thus, this study was aimed at answering these questions.

Thus, it was found out that, Political System, Political Will and Space, and Technical Capacity are the major statistically significant factors that affect the effectiveness of FDRE legislature in the public policy making process. One of the interesting findings is that all the three factors, beyond and above the overlapping effect, appear to have their own unique significant contributions to the prediction of the legislature's effectiveness throughout the public policy making process. Moreover, this study showed that political system is the most significant determinant factor of legislature's effectiveness in the policy making process in Ethiopia, followed by Political Will and Space, and Technical Capacity respectively. Similarly, the results indicate that three indicator variables namely: absence of opposition parties in the House, functioning with total freedom, and the adequacy of structural and administrative system of the House which were found as major statistically significant predictors of the variation in the 
legislature"s effectiveness in the descending order. Moreover, unlike the absence of opposition parties in the House, the other two indicators are positively associated with FDRE legislature's effectiveness. However, it's important that evidences provided by this study indicate that the FDRE legislators are not functioning with total freedom, as well as the structural and administrative system of the House is inadequate. Therefore, it is not a surprise that the FDRE legislature's effectiveness in the policy making processes is below the satisfactory level. In other words, it is can be concluded that absence of opposition parties in the House, lack of total freedom to undertake the legislation function as well as inadequacy of the structural and administrative system, are the major secrets behind the unsatisfactory effectiveness level of the FDRE legislature

On the basis of the findings, it was recommended that the following actions should be taken in a timely manner to make the FDRE legislature more effective. First, the electoral system and policy of the country should be revised so as to have a parliament that reflects diverse interests, concerns, and needs of the citizens throughout the policy process. There is also a strong need to have a room for opposition parties in the Ethiopian parliament. At least some seats should be reserved for opposition political parties. Secondly, since one of the reasons of the FDRE legislature ineffectiveness is lack of total freedom to undertake the legislative function, MPs have to be free from unnecessary intervention of the executive branch. The principle of separation of power should be practically ensured. Above all, as per the constitution MPs have to be practically loyal to the constitution, their conscience and the public. Thirdly, politicians should show their will to make the FDRE legislature an effective representative of the public. Those who held the highest political power should let the MPs to function with total freedom and responsibility. Fourthly, much attention must be given to reorganize the supporting staff with adequate human and material resources. The House should strive to establish a research unit and to have adequate and well trained professionals. Moreover, it needs to launch a system to work in collaboration with think-thanks, universities, and other related institutions. The legislature has to establish a system and need to use a variety of mechanisms to promote the publics' understanding and knowledge about the policy making processes as well as the role of major the actors' including the public itself. In this regard, a wider policy dialogue and public hearing platforms should be put in place.Using the mass media, proper management and use of its website, organizing public forums, planned and schedule visit of, for instance, might serve as mechanisms. Finally, it's recommended that a comparative policy study has to be carried out to assess the roles played by legislatures. For instance one can compare FDRE legislatures with other African countries that adopt parliamentary system.

\section{References}

Abebe, M. (2005). A Critical Assessment of Institutions, Roles and Leverage in Public Policy Making: Ethiopia 1974-2004 (Doctoral dissertation, PhD Dissertation), The University of Stellenbosch, South Africa).

Alemu, T. (2015). Policymaking Practice and Challenges of House of Peoples Representatives (HoPRs). Public Policy and Administration Research, Vol.5 (1), p.136-167.

Atsbeha Aregawi. (2012). The Practice of Policy Making process in Ethiopia: The Case of HPR.( Master's Thesis, AAU).

Awel, A. (2011). Parliamentary Oversight and Its Role In Ensuring Constitutionalism and Accountability Under the FDRE Constitution (Doctoral dissertation, AAU).

Barclay, D., R. Thompson, and C. Higgins (1995) "The Partial Least Squares (PLS) Approach to Causal Modeling: Personal Computer Adoption and Use an Illustration," Technology Studies (2)2, pp. 285-309.

Barkan, J. D., Adamolekun, L., \& Zhou, Y. (2004). Emerging legislatures: Institutions of horizontal accountability. Building state capacity in Africa: new approaches, emerging lessons, Washington, DC: World Bank Institute, 211-256.

Barkan, J. D. (Ed.). (2009). Legislative power in emerging African democracies. Lynne Rienner Publishers.

Beetham, D. (Ed.). (2006). Parliament and democracy in the twenty-first century: A guide to good practice. InterParliamentary Union.

Bolarinwa, Joshua, Olusegun, (2015). Emerging legislatures in Africa: challenges and opportunities.

Canfield-Davis, K., Jain, S., Wattam, D., McMurtry, J., \& Johnson, M. (2010). Factors of influence on legislative decision making: A descriptive study-updated August 2009. Journal of Legal, Ethical and Regulatory Issues, 13(2), 55.

Cochran, W.G. (1963). Sampling Techniques, $2^{\text {nd }}$ ED., New York: John Wiley and Sons, Inc.

Eberlei, W., \& Henn, H. (2008). Parliaments in Sub-Saharan Africa: Actors in Poverty Reduction? Study on behalf of the German Technical Cooperation (GTZ).

FDRE,(1995).The Federal Democratic Republic of Ethiopia Constitution. Proclamation No. 1, Negarit Gazette, 1 st Year, No. 1.

Fish, M. S. (2006). Stronger legislatures, stronger democracies. Journal of Democracy, 17(1), 5-20.

Franchino, F., \& Høyland, B. (2008). Legislative policymaking in parliamentary systems: Opportunities, conflict and institutional constraints. In Conference on" Designing Democratic Institutions'” (Vol. 13, p. 14).

Fornell, C. and D. Larcker (1981). "Evaluating Structural Equation Models with Unobservable Variables and 
Measurement Error," Journal of Marketing Research (18)1, pp. 39-50.

Gray, D. E. (2013). Doing research in the real world. Sage.

Hair, J. F., Jr., R. E. Anderson, R. L. Tatham, and W. C. Black. (1998). Multivariate Data Analysis with Readings, 5th Edition. Englewood Cliffs, NJ: Prentice Hall.

Johnson, J. K. (2005). The Role of Parliament in Government. World Bank Institute, Washington, DC.

Johnson, J. K., \& Nakamura, R. (1999). A Concept Paper on Legislatures and Good Governance. New York, USA: UNDP (United Nations Development Programme).

Kahsay, M. (2013). The Legislative Process in Ethiopia: Challenges and Prospects (Doctoral dissertation, AAU).

Korris, M. (2011). Standing up for scrutiny: How and why parliament should make better law. Parliamentary Affairs, gsr016.

Onigbinde, A. (2000). 'Monitoring the Implementation of Budget by the Legislature', Paper Presented at the Workshop on 'Appropriate Handling of Budgeting by the Legislature', for Members of the Osun State House of Assembly, Nigeria, held at MicCom-Golf Resort, Ada, Osun State, Nigeria, 15th January.

Remini, R. V. (2007). The House: The History of the House of Representatives. Harper Collins.

Regulation No.6/2008, the Regulation of Working Procedures and the Members Code of Conduct of House of Peoples Representatives.

Saiegh, S. M. (2005). The role of legislatures in the policymaking process.Presentado al Taller del Banco Interamericano de Desarrollo sobre la Reforma de Estado, las políticas públicas y los procesos de formulación de políticas, Washington, DC.

Szilágyi, I. M. (2009). Presidential versus parliamentary systems. AARMS, Vol. 8, No. 2, 307-314

United Nations. Economic Commission for Africa. (2005). African Governance Report 2005 (Vol. 5). United Nations Publications.

USAID. (2000). USAID Handbook on Legislative Strengthening. http://www.usaid.gov/our-work/democracy and governance /publications /pdf/ pnacf632.pdf. Retrieved on 13 October 2015.

Annex A: Standardized Factor Loadings of observed variables/ Items

\begin{tabular}{|c|c|c|}
\hline No & Construct Statements & Standardized Factor Loading $(\Lambda)$ \\
\hline \multicolumn{3}{|c|}{ Political system (PS) } \\
\hline 1 & PS1 & .88 \\
\hline 2 & PS2 & .86 \\
\hline 3 & PS3 & .83 \\
\hline 4 & PS4 & .80 \\
\hline \multicolumn{3}{|c|}{ Political will and space (PWS) } \\
\hline 5 & PWS1 & .80 \\
\hline 6 & PWS2 & .83 \\
\hline 7 & PWS3 & .70 \\
\hline 8 & PWS4 & .74 \\
\hline \multicolumn{3}{|c|}{ Technical capacity (TC) } \\
\hline 9 & TC1 & .77 \\
\hline 10 & TC2 & .60 \\
\hline 11 & TC3 & .66 \\
\hline 12 & TC4 & .67 \\
\hline \multicolumn{3}{|c|}{ Legislative effectiveness (IEF) } \\
\hline 13 & LE1 & .96 \\
\hline 14 & LE2 & .85 \\
\hline 15 & LE3 & .90 \\
\hline 16 & LE4 & .73 \\
\hline
\end{tabular}

Source: survey data, 2016

Note: All Factor loadings are significant at $\mathrm{p}<0.01$ 


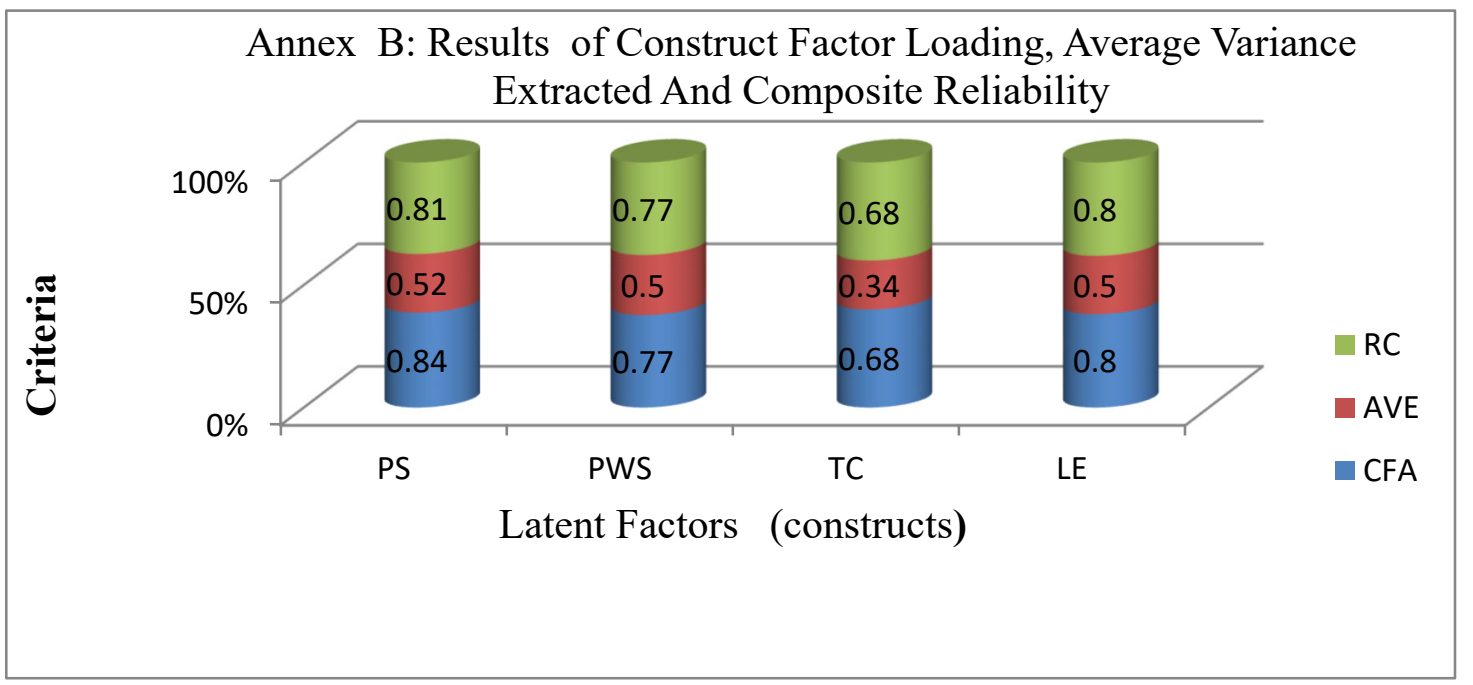

Annex C: Goodness-of-fit statistics Summary of the Measurement Model

\begin{tabular}{|c|c|c|}
\hline Fit statistic & Recommended value & Obtained value \\
\hline AGFI & $>.90$ & .863 \\
\hline CFI & $>.90$ & .976 \\
\hline RFI & $>.90$ & .912 \\
\hline TLI & $>.90$ & .969 \\
\hline RMSEA & $<0.05($ or $<0.08)$ & .062 \\
\hline
\end{tabular}

Annex D: Annex I: Result for Assumptions of Normality, Linearity, and Homoscedasticity Histogram

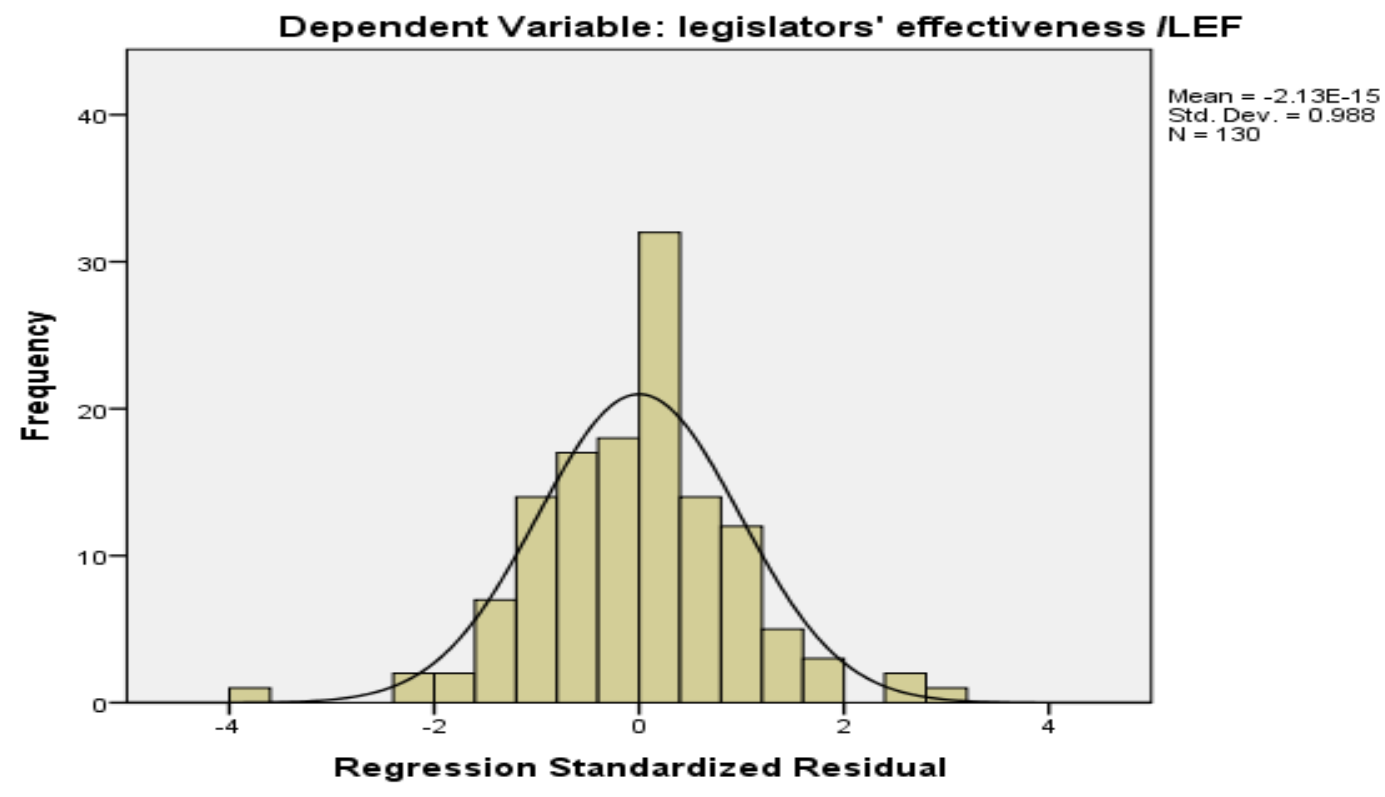


Scatterplot

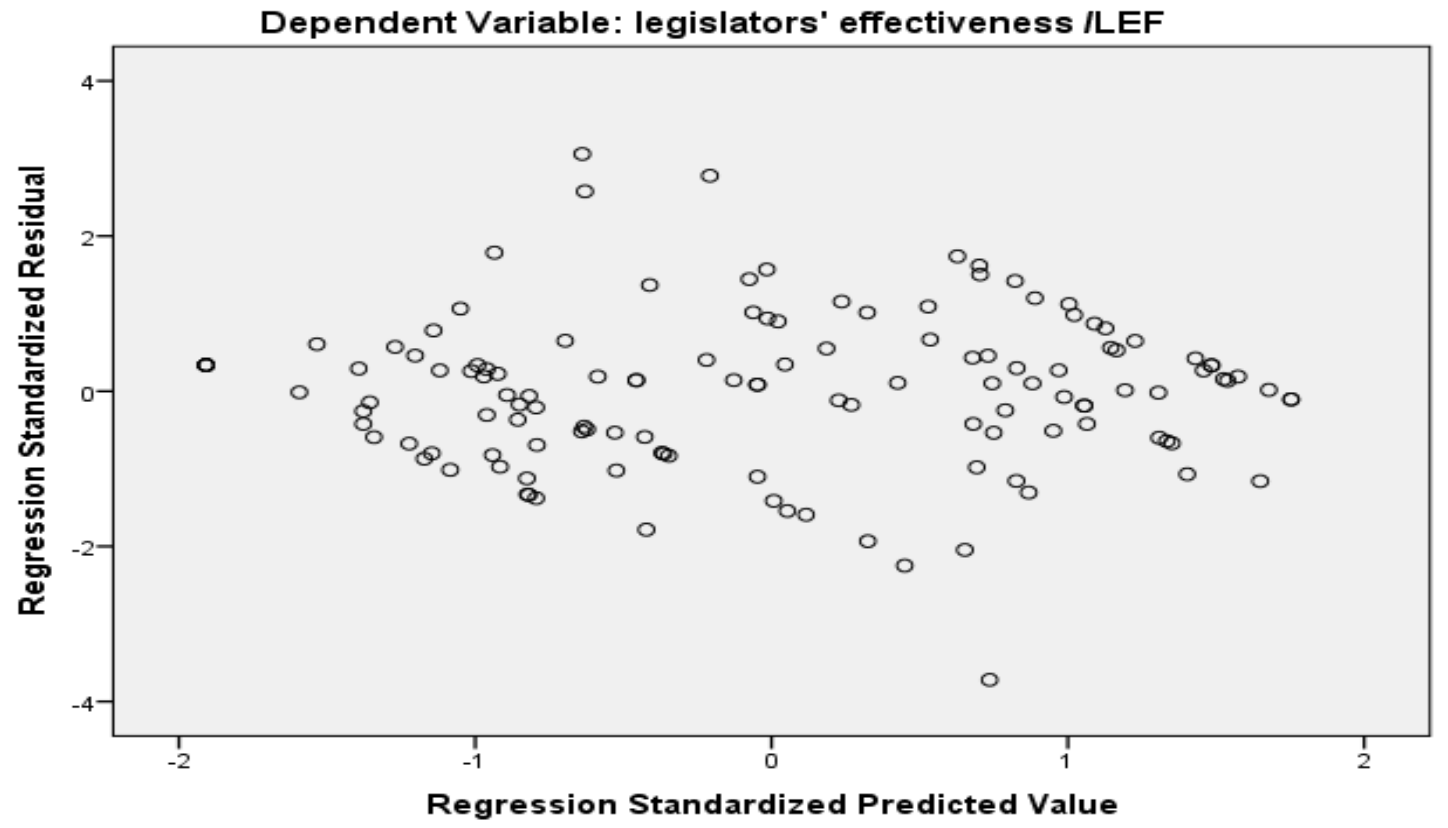

Annex E : Coefficients and Multicollinearity: Tolerance and Variance Inflation Factor (VIF)

\begin{tabular}{|c|c|c|c|c|c|c|c|c|}
\hline \multirow[t]{2}{*}{ Model } & \multicolumn{2}{|c|}{$\begin{array}{c}\text { Unstandardized } \\
\text { Coefficients }\end{array}$} & $\begin{array}{c}\text { Standardized } \\
\text { Coefficients }\end{array}$ & Sig. & \multicolumn{2}{|c|}{ Correlations } & \multicolumn{2}{|c|}{ Collinearity Statistics } \\
\hline & $\mathrm{B}$ & Std. Error & Beta & & Zero-order & Part & Tolerance & VIF \\
\hline (Constant) & 2.510 & .072 & & .000 & & & & \\
\hline Polsyst & .862 & .053 & .823 & .000 & .823 & .823 & 1.000 & 1.000 \\
\hline (Constant) & 2.377 & .076 & & .000 & & & & \\
\hline \multirow[t]{3}{*}{2} & .421 & .121 & .402 & .001 & .823 & .166 & .170 & 5.890 \\
\hline & .661 & .165 & .462 & .000 & .828 & .190 & .170 & 5.890 \\
\hline & 2.545 & .092 & & .000 & & & & \\
\hline \multirow[b]{3}{*}{$1 \mathrm{ecr}$} & .409 & .117 & .390 & .001 & .823 & .161 & .170 & 5.897 \\
\hline & .431 & .176 & .302 & .016 & .828 & .112 & .139 & 7.185 \\
\hline & -.413 & .134 & -.222 & .003 & -.732 & -.141 & .405 & 2.470 \\
\hline
\end{tabular}

a. Dependent Variable: legislators' effectiveness /LEF 